\title{
\& ditorial \\ La demografía profesional en España: cabalgando un tigre
}

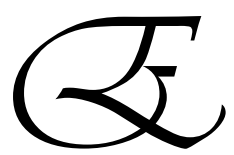

n la actualidad existen en España quince facultades de odontología, once de ellas de titularidad pública y las cuatro restantes privadas. De acuerdo a los últimos datos disponibles del Instituto Nacional de Estadística y que corresponden al curso 2000-2001, el total de alumnos matriculados era de 6427, y de ellos, casi la mitad -3069- eran estudiantes de las tres facultades privadas que estaban en funcionamiento en aquel momento. A día de hoy, con la puesta en marcha de las dos nuevas facultades públicas, Salamanca y Juan Carlos I en Alcorcón, y la privada Cardenal Herrera en Valencia, el número de estudiantes de odontología en las universidades españolas estará cercano a los 7000. El número de odontólogos colegiados en nuestro país, de acuerdo a la misma fuente-INE- era en el año 2000 de 17.538, así pues el total de alumnos de odontología representaba más del 40\% de la colegiación en España, en cifras oficiales.

Esta situación, que es real y no fruto de un análisis de proyección demográfica y que debería complementarse con la de los titulados extranjeros homologados, es a mi juicio preocupante y merecedora de un análisis y unas reflexiones más profundas que la de este editorial del monográfico de Odontología Preventiva y Comunitaria.

En la Unión Europea, Grecia es junto con Finlandia el país con una mayor proporción de dentistas por habitante, 1 dentista por cada 1.000 habitantes. Sin embargo Grecia es también uno de los países europeos con una frecuentación más baja al dentista, es decir que un mayor número de dentistas no garantiza una mayor utilización de los servicios odontológicos ${ }^{1}$.

En España la frecuentación al dentista y el gasto por paciente es muy inferior a la media europea, sin embargo nuestra demografía profesional, en relación al número de habitantes es ya superior a la de países con mayor desarrollo económico y socio-sanitario, como el Reino Unido .
En un muy interesante artículo publicado en este número de nuestra revista, Bravo ${ }^{2}$ señala que durante el período comprendido entre 1987 y 1997 el número de dentistas en España se ha bía incrementado en un $136 \%$ durante ese mismo espacio de tiempo el número total de visitas privadas al dentista había aumentado en un $36 \%$ sin embargo, y como consecuencia del enorme crecimiento en la demografía profesional, el porcentaje de visitas por dentista había disminuido en un 42\% Así pues, el aumento de demanda de servicios odontológicos creció muy por debajo de la oferta de esos senvicios.

Ante un aumento de la oferta de servicios sanitarios, los proveedores, en este caso los dentistas, responden con un aumento de la demanda inducida como mecanismo para mantener sus niveles de ingresos, este es un fenómeno ampliamente estudiado y bien documentado en los textos de Economía Sanitaria. Sin embargo la práctica sistemática de la demanda inducida tiene unos límites y unos riesgos, los límites -lo que los economistas denominan elasticidad de la demanda- los marca la propia economía entre otros, y los riesgos, en forma de sobre-tratamiento, lo son para la salud. La no enfermedad es incurable y toda actividad terapéutica encaminada a curar la no enfermedad es nociva3.

El crecimiento explosivo de la demografía profesional, es uno de los retos más importantes a los que se va a enfrentar la profesión organizada en el futuro inmediato y de su solución va a depender el futuro profesional de muchos odontólogos y los niveles de atención en salud bucal de muchos de nuestros conciudadanos.

Emili Cuenca Sala Director Asociado

1. http://www.oecd.org/document/30/0,234,en 264934631129687341

2. Bravo M. Desigualdades geográficas en las cargas de trabajo por dentista en España entre 1987 y 1997.RCOE 2004;9...

3. Skrabanek J, McCormick J. Sofismas y desatinos en Medicina. Barcelona: Doyma,1992 